\title{
REVIEW ON AEROELASTICITY
}

\section{Nithin S}

Department of Aerospace Engineering Alliance University, Bengaluru, Karnataka, India

\begin{abstract}
Aeroelasticity phenomena involve the study of the interaction between aerodynamic forces and elastic forces (static aeroelasticity), aerodynamic forces, inertia forces and elastic forces (dynamic aeroelasticity), and aerodynamic forces, inertia forces, elastic forces and control laws (aeroservo-elasticity). Modern aircraft structures may be very flexible and this flexibility of the airframe makes aeroelastic study an important aspect of aircraft design and verification procedures. Wing torsional divergence and flutter are the two major aeroelastic phenomena considered in aircraft design. Divergence is a static instability which occurs when the static aerodynamic effects counteract the torsional stiffness of the structure. Flutter is a dynamic aeroelastic instability characterized by sustained oscillation of structure arising from interaction between the elastic, inertial and aerodynamic forces acting on the body. The present paper gives a fragrance of static and dynamic aeroelasticity problems aiming the readers to get an idea about the subject.
\end{abstract}

Keywords - Aeroelasticity, Static Aeroelasticity, Dynamic Aeroelasticity, Mechanical Vibrations, Aircraft design.

\section{INTRODUCTION}

The term aeroelasticity is applied to an important class of problems in airplane design. The flexible airframe causes a greater interaction between the structural flexibility and aerodynamics. It involves the study of the interaction between aerodynamic forces, elastic forces, inertia forces and control system dynamics. Such an interaction may be static (such as during a steady level flight or during a trimmed maneuver) or dynamic (involving variations with time) and participation of inertia forces in addition to the elastic, aerodynamic and control forces in the system dynamics.

Fig. 1 shows a typical aeroelastic interaction triangle. Aeroelasticity problems would not exist if airplane structures were perfectly rigid. Modern aircraft structures may be very flexible and this flexibility of the airframe makes aeroelastic analyses an important aspect of aircraft design and verification procedures. Aeroelastic behavior is also influenced by thermal effects (aerothermoelasticity) and by the influence of closedloop control feedback effects (aeroservoelasticity). Other topics involving dynamic aeroelastic effects are: gusts, buffeting, store release etc.
Vijayalakshmi Bharathi K

Department of Aerospace Engineering

Alliance University, Bengaluru, Karnataka, India

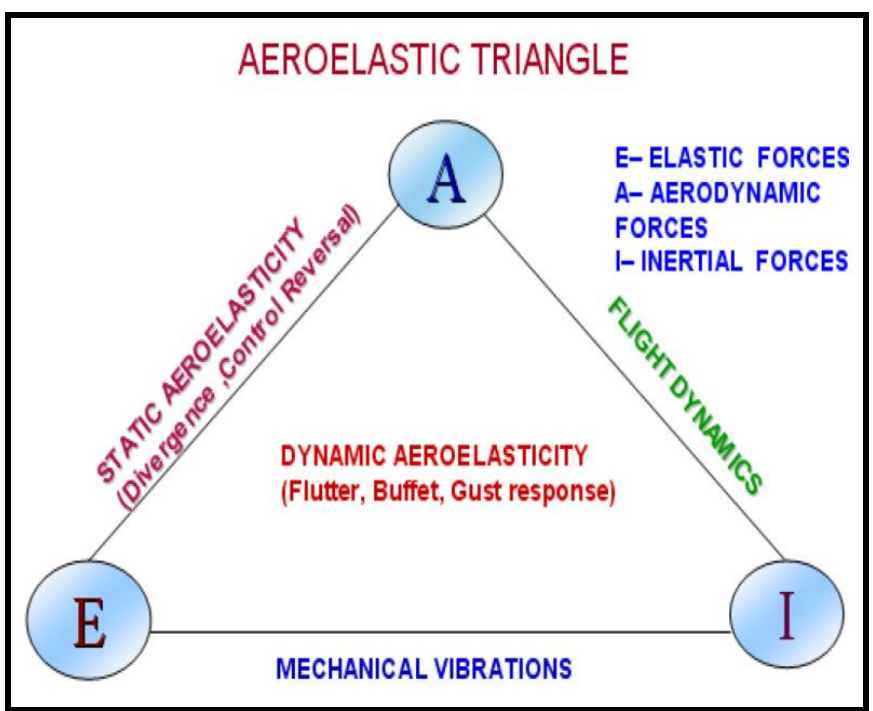

Figure 1: Aeroelasticity interaction triangle

\section{HISTORY OF AEROELASTICITY}

In the history of aviation, Samuel Langley's aircraft configuration was a tandem-wing design with an aft-mounted tail unit for stability and control [1] [3] [9].These airplanes were called Aerodromes by Langley (Fig. 2).

As Fig. 2 shows, the wings had a significant dihedral angle to provide lateral stability. In fact, Langley's design philosophy was to provide the airframe with inherent stability, independent of pilot input. As it was done with the scale models, it was launched from a houseboat-mounted catapult. However, the Aerodrome quickly dove into the river, with no flight being achieved.

As aeronautical technology progressed, including an understanding of aeroelastic effects, the notion grew that the Great Aerodrome's failure was due to wing torsional divergence. Nine days later December 17, 1903 the Wright brothers flew, and Langley's quest for flight was over (Fig. 3). In 1914, Curtis made some modification of Langley's Aerodrome and flew successfully. 


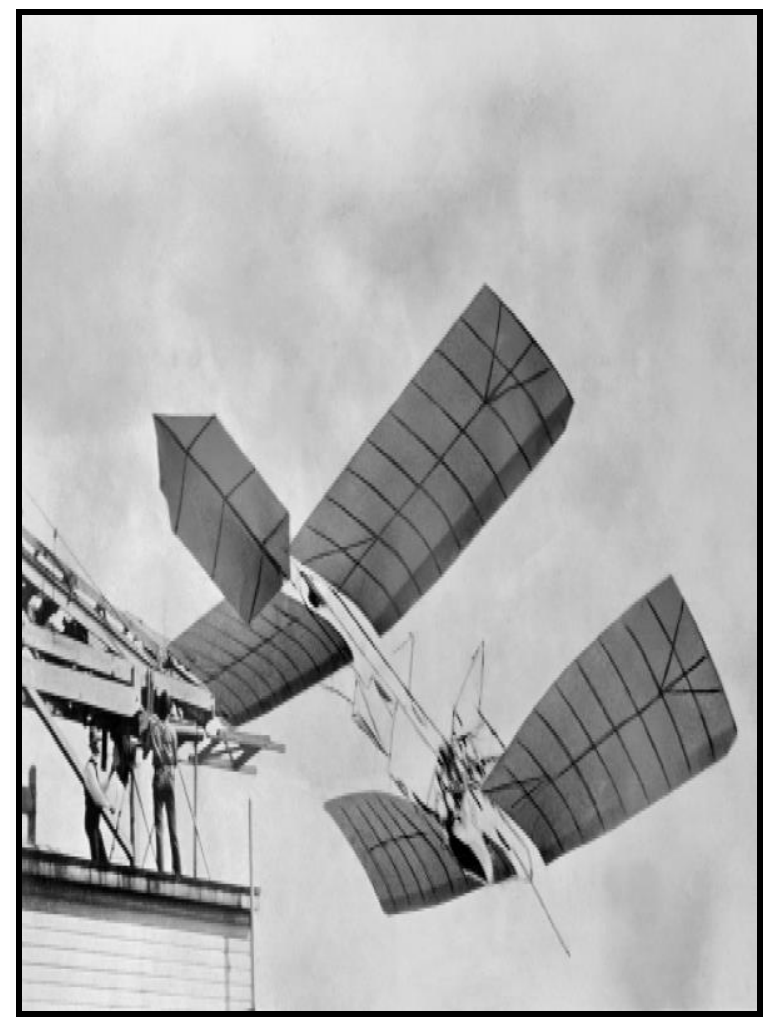

Figure 2: Langley's Aerodrome

Fokker D-8 had great performance but suffered from wing failures in steep dives (Fig. 4). Early monoplanes had insufficient torsional stiffness resulting in wing flutter, wingaileron flutter, and loss of aileron effectiveness. The solution found was to increase torsional stiffness, and mass balancing [2].

First recorded flutter incident involved Hadley Page's 0/400 Bomber Bi-plane (Fig. 5) in 1915 with 'violent oscillations' of the tail flutter problem occurred due to fuselage torsion coupled with elevators[3][4].

The first formal flutter test was carried out by Von Schlippe in 1935 in Germany (vibrate the aircraft at resonance frequencies at progressively higher speeds and plot amplitude as a function of speed). The above idea was applied to many German aircrafts until a Junkers JU 90 fluttered and crashed during flight tests in 1938 .

Presently, the sophisticated analytical techniques are used to ensure that the design is free from flutter with in the flight envelope. These results are verified by wind tunnel flutter model and ground vibration tests. Flight flutter testing provides the final verification of analytical predictions throughout the flight envelope.

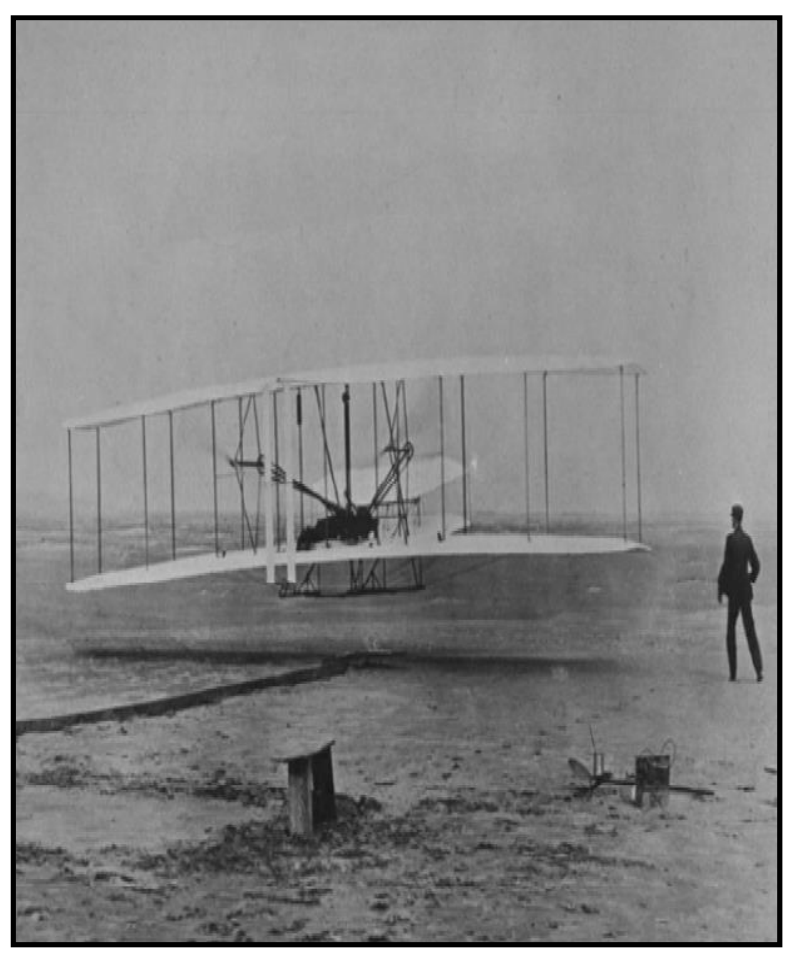

Figure 3: Wright brother's Bi-plane aircraft

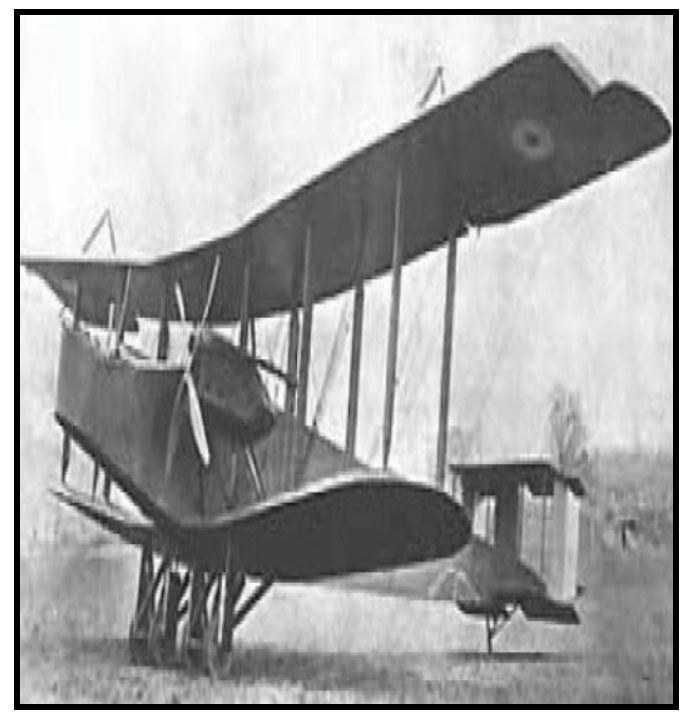

Figure 4: Bomber Bi-plane

\section{STATIC AEROELASTICITY}

The interaction between Aerodynamic forces \& elastic nature of materials is called as static aeroelasticity. The two major problems of static aeroelasticity are divergence and aileron reversal. The latter also called aileron ineffectiveness. A brief 


\section{International Journal of Engineering Applied Sciences and Technology, 2019 \\ Vol. 4, Issue 8, ISSN No. 2455-2143, Pages 271-274 \\ Published Online December 2019 in IJEAST (http://www.ijeast.com)}

coverage will be given here to show how this interaction leads to aeroelasticity phenomena.

\section{A. Divergence}

For an aerodynamic surface (e.g., wing or tail), the aerodynamic force normal to the airstream (usually called lift) increases with (speed) ${ }^{2}$ and with the angle of incidence (the angle between the surface and the flow direction) as shown in Fig. 6 for a cross section of the surface. The lift will normally cause the surface to twist leading edge up if the surface is flexible because the center of pressure on the section is usually forward of the elastic axis (i.e., axis of twist) as shown in Fig. 7. The twist causes the angle presented by the surface to the airstream to increase; therefore the aerodynamic force increases further, increases the twist further and so on until an equilibrium condition is reached.

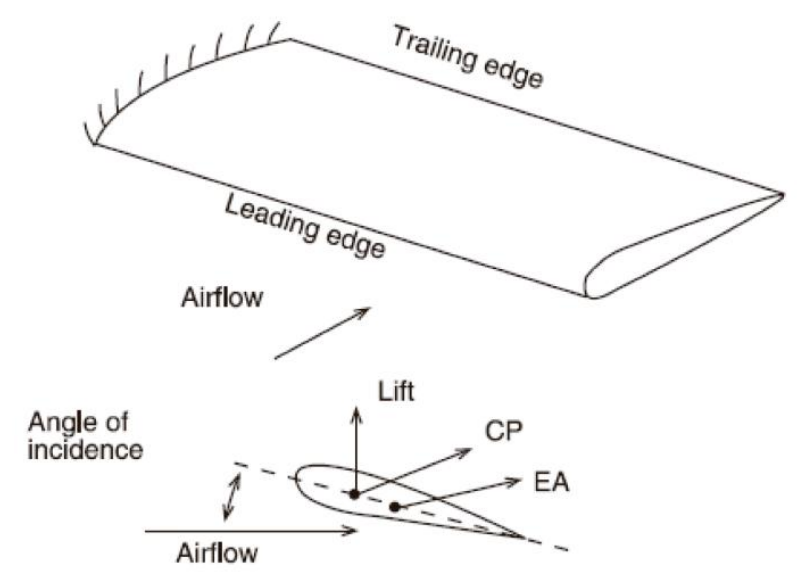

Figure 6: Aerodynamic notations, Centre of pressure (CP), Elastic Axis (EA)

Divergence occurs when a lifting surface deflects under aerodynamic load so as to increase the applied load, or move the load so that the twisting effect on the structure is increased. The increased load deflects the structure further, which brings the structure to the failure[4][5].

\section{B. Aileron reversal}

When the aileron is deflected downward, an upward lift is created. This lift in turn will cause a moment about the elastic axis as shown in Fig. 8. That moment will rotate the wing section in a nose-down direction. In turn, this elastic rotation will induce a down lift on the wing section. If the commanded up- lift (due to the aileron deflection) exceeds the down-lift due to the aeroelastic rotation, the aileron is said to have reversed. Clearly, such aileron reversal is not acceptable within the normal flight envelop of an airplane.

\section{DYNAMIC AEROELASTICITY}

Dynamic aeroelasticity concerns the interaction between inertia, elastic, and unsteady aerodynamic forces. This dynamic problem is more complex than static aeroelasticity, since vibration of the structure is also involved. Flutter is an important dynamic aeroelasticity phenomenon and discussed here.

A. Flutter instability
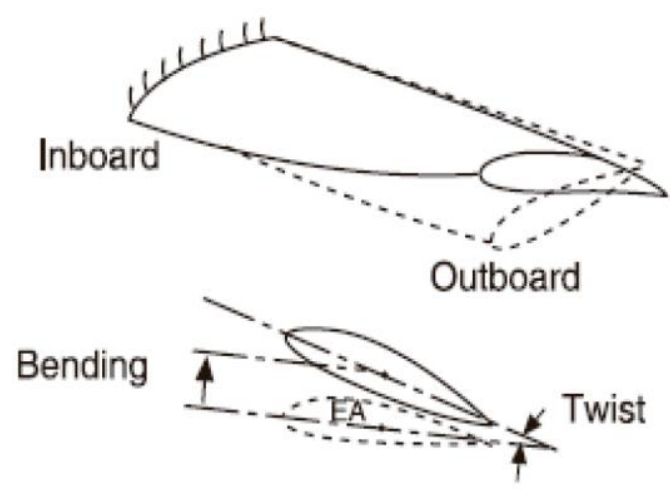

Figure 7: Aerodynamic surface deformation

Flutter, a mode of dynamic instability has the most farreaching effects of all aero elastic phenomena on the design of high speed aircraft. The classical type of flutter is associated with potential flow and usually involves the coupling of two or more degrees of freedom. However, in modern aircraft configurations with vortex dominated flows may involve separated flow, periodic break away and reattachment of flow, stalling conditions, besides various time-lag effects between the aerodynamic forces and the motion. The theoretical evaluation of flutter characteristics of an aircraft in a given flight envelope assumes primacy from the viewpoints of flight safety and structural integrity, as well as controllability.

Accordingly, flutter analysis requires extensive computations under wide parametric variations corresponding to different mass \& structural configurations and aerodynamic states (described through speed and density variations) to conform to the defined flight envelope. In the analysis, the establishment of the natural vibration-modes of the structure, typically using Finite Element (FE) procedures, constitutes the first step; the integration of the aerodynamic forces acting on the structure into the aeroelastic equations, and subsequently, their solution for flutter forms the second step[6][7][8].

\section{B. Buffeting}

It is high frequency instability caused by airflow separation or by shock wave oscillation from one object striking other and by a sudden impulse of load. It is a random forced vibration and generally it effects the tail part of the aircraft due to flow downstream the wing[10]. 


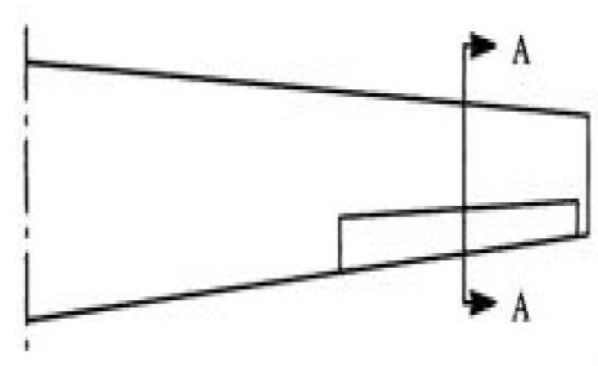

Elastic axis

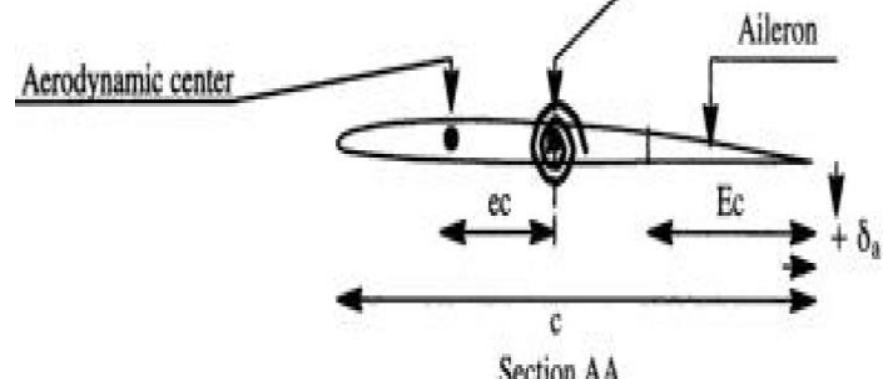

Section AA

Figure 8: Two dimensional aileron reversal

\section{CONCLUSION}

The Aeroelasticity is an advanced topic in aerospace engineering. Aeroelasticity plays an important role in designing the modern aircraft especially fighter aircraft. The present paper gives a fragrance of static and dynamic aeroelasticity problems aiming the readers to get an idea about the subject. This paper covers the general aeroelastic phenomena including divergence and aileron reversal.

\section{ACKNOWLEDMENT}

The authors would like to acknowledge Alliance college of Engineering \& Design for immense support \& encouragement in carrying out this work.

\section{REFERENCE}

[1] L. Auriti, and J. DeLaurier, November-December 2004 "Analysis of the Flight Attempt by Samuel Langley's Great Aerodrome," Journal of Aircraft, vol. 41, No. 6, pp. 14301439

[2] Ray Kolonay. http://www.ae.metu.edu.tr/ yyaman/avt086/Kolonay/

[3] R.L.Bisplinghoff, Holt Ashley and R.L. Halfman,1996, Aeroelasticity, Units 1,2,3,4, Dover Publications Inc

[4] Theodore von Kármán (1967) The Wind and Beyond, page 155.
[5] The adequacy of comparison between flutter in aircraft aerodynamics and Tacoma Narrows Bridge case is discussed and disputed in Yusuf K. Billah, Robert H. Scanian, "Resonance, Tacoma Bridge failure, and undergraduate physics textbooks"; Am. J. Phys. 59(2), 118-124, February 1991.

[6] E. E. Sechler (1952) Elasticity in Engineering.

[7] Collar, A. R. (1978). "The first fifty years of aeroelasticity". Aerospace. vol. 5, no. 2, pp. 12-20, 1978.

[8] Garrick, I. E. and Reed W. H., "Historical development of aircraft flutter", Journal of Aircraft, vol. 18, pp. 897-912, Nov. 1981.

[9] Aeroelasticity Branch - NASA Langley Research Center [Online] Available https://aeroelasticity.larc.nasa.gov/

[10] National Aerospace Laboratory https://web.archive.org/web/20110811003313/http://www.nlr. $\underline{\text { nl/smartsite.dws?l=en \&id }=9041}$

[11] Historical Development of Aircraft Flutter; I. E. Garrick and Wilmer H. Reed III; Volume 18

[12] Historical Development of Aircraft Flutter; Article in Journal of Aircraft 18(11):897-912 